\title{
Adsorption of Lead lons from Aqueous Solutions onto Rice Husks, Continuous System
}

\author{
Laith Hamdan Hawal ${ }^{1 *}$, Ali Omran Al-Sulttani ${ }^{2}$, Nagam Obaid Kariem¹ \\ 1 Environment Engineering Department, Mustansiriyah University, Baghdad, Iraq \\ 2 Water Resources Engineering Department, College of Engineering, University of Baghdad, Baghdad, Iraq \\ * Corresponding author's e-mail: laith.h@uomustansiriyah.edu.iq
}

\begin{abstract}
The continuous system of lead adsorption on rice husks was investigated in this paper. A fixed bed study was performed in many tests to investigate the influence of $\mathrm{pH}$, the adsorbent height, the initial concentration of lead, the flow rate and processing time on the lead adsorption process. The results demonstrated that the lead removal capacity decreased when the $\mathrm{pH}$ value of the solution and the flow rate increased. The lead removal capacity increased due to the decreased initial concentration of lead. The results showed that the removal capacity increases along with the processing time and the adsorbent height in column. The largest removal was (81\%) at $\mathrm{pH}$ of 4 , the adsorbent height $(50 \mathrm{~cm})$, the initial concentration of lead $(10 \mathrm{mg} / \mathrm{l})$, the processing time $(90 \mathrm{~min}$.) and the flow rate $(10 \mathrm{ml} / \mathrm{min}$.). As a result, rice husks can be used to remove the lead instead of expensive commercial adsorbents, due to its availability, inexpensive and perfect adsorption property.
\end{abstract}

Keywords: adsorption, lead, rice husks, removal capacity, $\mathrm{pH}$

\section{INTRODUCTION}

The problem of pollution with toxic metals is one of the environmental problems resulting from human activities such as mining, agriculture waste and industry. The effluents from mining, metal plating, battery manufacturing, and smelting are the main supplier of metals in the water. Heavy metals are among the most dangerous pollutants on Earth's surface. The heavy metals that are most troublesome include cadmium $(\mathrm{Cd})$, copper $(\mathrm{Cu})$, zinc $(\mathrm{Zn})$, lead $(\mathrm{Pb})$, arsenic $(\mathrm{As})$ and nickel (Ni). They are widespread and processing these elements is a matter of urgency. These pollutants are discarded to the environment, reaching high concentrations that exceed the acceptable limits in the international laws. Hence, it is the water resources that are most exposed to the risks of their high diffusion. The heavy metals existing in high concentrations in industrial wastes after being introduced may cause biological, physical and chemical changes in the water bodies composition, such as changes in $\mathrm{pH}$, increased oxygen demand, turbidity and others (Burakov et al. 2018, Hawal et al. 2021a, Hawal et al. 2021b, Dos Santos et al. 2010). There are various poisonous and cancerous metals, and they easily percolate to food chain (Hawal et al. 2021c). It can also lead to the death of many organisms, in addition to the serious impact on the specifications of water required for human consumption. In high concentrations, the toxic impact of these heavy metals on living organisms results from the inhibition or obstruction of biological activities, causing severe and irreversible damage (Burakov et al. 2018).

There are several methods that can be used to remove lead ions from aqueous solutions, such as electrochemical processing, chemical precipitation, chemical oxidation and reduction, evaporative recovery, ion exchange and filtration. However, these high-tech methods have great disadvantages such as incomplete heavy metal removal, require expensive monitoring systems and equipment, and produce toxic sludge and other wastes that must be disposed of (Patterson 1985). In the past few years, the adsorption technology 
has been broadly used to eliminate heavy metals ions from industrial and domestic effluents (Tarasevich and Klimova 2001).

For industrial effluent treatment, adsorption in continuous system is preferable (Kundu and Gupta 2005). Therefore, the experimental laboratory results obtained by fixed bed column are useful in designing a continuous system of adsorption for industrial applications. Rice husks are hard, protective covers over the rice grains. The husk is made of solid materials, including lignin and opaline silica, protecting the seeds during the growing seasons. It is mostly indigestible for humans. The husks are removed during the cereal production process to produce brown rice. Rice husks are a class (A) insulation because they are less likely to be exposed to moisture and mold or fungi as well as difficult to burn. When rice husks are burned, they produce large quantities of silica element. After burning, the extremely high content of amorphous silica of the husks gives it and its ash very good properties for thermal insulation (Nakbanpote et al. 2007).

The goals of this paper were to: (1) study the possibility of using rice husks as an available and cheap adsorbent for lead adsorption, (2) study the effect of $\mathrm{pH}$ value, adsorbent height in column, initial contaminant concentration, processing time and flow rate on the efficiency of the adsorption process.

\section{MATERIALS AND METHODS}

\section{Rice husks}

Rice husks (RH) were taken from the local rice industries. The rice husks were washed with tap water and then dried at $105^{\circ} \mathrm{C}$ for one day to remove their moisture content. The dried rice husks were ground and sifted to a size of (1-2 $\mathrm{mm})$. Then, 5 grams of rice husks were mixed with $95 \mathrm{ml}$ of aqueous solution $(3 \% \mathrm{NaOH})$ in a volumetric flask $(250 \mathrm{~mL})$ and heated at $110{ }^{\circ} \mathrm{C}$ for $40 \mathrm{~min}$. After that, the rice husks mixture was filtered and washed by distilled water; then it was dried and kept (D. Yadav et al. 2018)

\section{Lead stock solutions}

A stock solution of lead $1000 \mathrm{mg} / \mathrm{l}$ was prepared by diluting 1.6 grams of lead nitrate in one liter of deionized water. Concentrations of (10,
$50,75$ and $100 \mathrm{mg} / \mathrm{l})$ were prepared by suitable dilution of solution by deionized water.

\section{Fixed bed column system}

The continuous system contains a container made of plastic (10 liters) with an outlet and an inlet, Plexiglas column (D: $2.6 \mathrm{~cm}$ and h: $60 \mathrm{~cm}$ ) and a Rotameter to measure the solution flow rate. A Plexiglas column was filled with adsorbent (rice husks) at required height for each experiment. It was washed with distilled water three times before starting each experiment. After that, it was filled by adsorbent media (rice husks) to the required depth. At the beginning of the experiment, the stock solution was permitted to flow downward by the effect of gravity through the column under the required conditions $(\mathrm{pH}$, adsorbent height, initial lead concentration, contact time and flow rate), as shown in Figure 1.

In order to achieve the best possible conditions for the adsorption technique in this study, the tests were conducted at $\mathrm{pH}(4-10)$, adsorbent height $(10-50 \mathrm{~cm})$, initial lead concentrations ( $10-100 \mathrm{mg} / \mathrm{l})$, the processing time (10-90 $\mathrm{min})$, the flow rate $(10-60 \mathrm{ml} / \mathrm{min})$ and at a temperature $\left(25^{\circ} \mathrm{C}\right)$ The samples were taken from the bottom of the column during each test. After that, the lead concentrations in those collected samples were determined by an atomic absorption spectroscopy. Table 1 explains the experimental conditions.

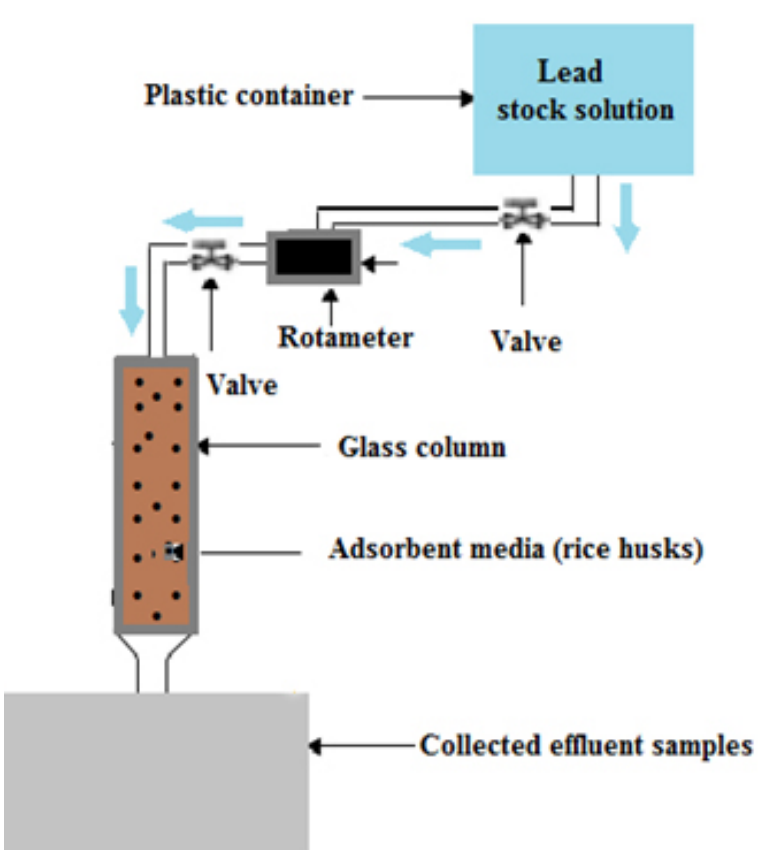

Figure 1. Sketch of continuous system 
Table 1. Conditions of the experiments

\begin{tabular}{|c|c|c|c|c|c|c|}
\hline EX. NO. & $\begin{array}{c}\text { Initial lead conc. } \\
(\mathrm{mg} / \mathrm{l})\end{array}$ & $\mathrm{pH}$ of solution & $\begin{array}{c}\text { Adsorbent bed } \\
\text { height }(\mathrm{cm})\end{array}$ & $\begin{array}{c}\text { Flow rate } \\
(\mathrm{ml} / \mathrm{min})\end{array}$ & $\begin{array}{c}\text { Processing time } \\
(\mathrm{min})\end{array}$ & Objective of Exp. \\
\hline EX-1 & 10 & $4-10$ & 50 & 10 & 90 & Influence of $\mathrm{pH}$ \\
\hline EX-2 & 10 & 4 & $10-50$ & 10 & 90 & $\begin{array}{c}\text { Influence of } \\
\text { adsorbent height }\end{array}$ \\
\hline EX-3 & $10-100$ & 4 & 50 & 10 & 90 & $\begin{array}{c}\text { Influence of initial } \\
\text { concentration }\end{array}$ \\
\hline EX-4 & 10 & 4 & 50 & 10 & $10-90$ & $\begin{array}{c}\text { Influence of } \\
\text { processing time }\end{array}$ \\
\hline EX-5 & 10 & 4 & 50 & $10-60$ & 90 & $\begin{array}{c}\text { Influence of flow } \\
\text { rate }\end{array}$ \\
\hline
\end{tabular}

\section{RESULTS AND DISCUSSIONS}

The lead absorption experiments were conducted in a fixed bed column (continuous system) and under different conditions. The tests were achieved at a temperature of $\left(25^{\circ} \mathrm{C}\right)$, the $\mathrm{pH}$ of solution, the adsorbent height (h), the initial concentration of lead $\left(\mathrm{C}_{\mathrm{o}}\right)$, the flow rate $(\mathrm{Q})$ and the processing time $(\mathrm{t})$. The removal percentage of lead was calculated according to the equation:

$R P(\%)=\frac{\text { Initial concentr. }- \text { Residual concentr. }}{\text { Initial concentr. }} \cdot 100 \%$

\section{Influence of $\mathrm{pH}$}

The $\mathrm{pH}$ value has a great influence on the adsorption technique. This effect was studied during some tests by varying the $\mathrm{pH}$ value between 4 to 10 . The tests were conducted at $\left[\mathrm{C}_{0}\right.$ $(10 \mathrm{mg} / \mathrm{l}), \mathrm{t}(90 \mathrm{~min}), \mathrm{Q}(10 \mathrm{ml} / \mathrm{min})$ and $\mathrm{h}(50$ $\mathrm{cm})$ ]. The lead adsorption from the solution is affected by the $\mathrm{pH}$ value, effect of adsorbent surface charge, degree of the ionization and the types of adsorbents. This may be due to the dependency of lead ionization on the value of $\mathrm{pH}$. The efficiency of the lead adsorption process is minimal when the $\mathrm{pH}$ value is high, this occurs due to prevailing driving force at high $\mathrm{pH}$. When the $\mathrm{pH}$ of the solution is high, ionized lead salts form simply. Therefore, it leaves a negative charge on the lead ions (Kouakou et al. 2013). The presence of $\mathrm{OH}$ ion on the surface of the adsorbing medium impedes the adsorption of lead ions. The $\mathrm{pH}$ value has an influence on the properties of the adsorbed surface. When $\mathrm{pH}$ drops, the surface of the adsorbent will be surrounded by hydronium ions; this will enhance the interaction of the lead ion with the absorbent binding sites through greater attraction forces (Kermani et al. 2009). Therefore, the percentage of lead adsorption decreases when the $\mathrm{pH}$ of the solution increases, as displayed in Figure 2.

\section{Influence of adsorbent height}

The influence of the adsorbent height was studied by varying the material height in the column, where the height ranges between 10 and

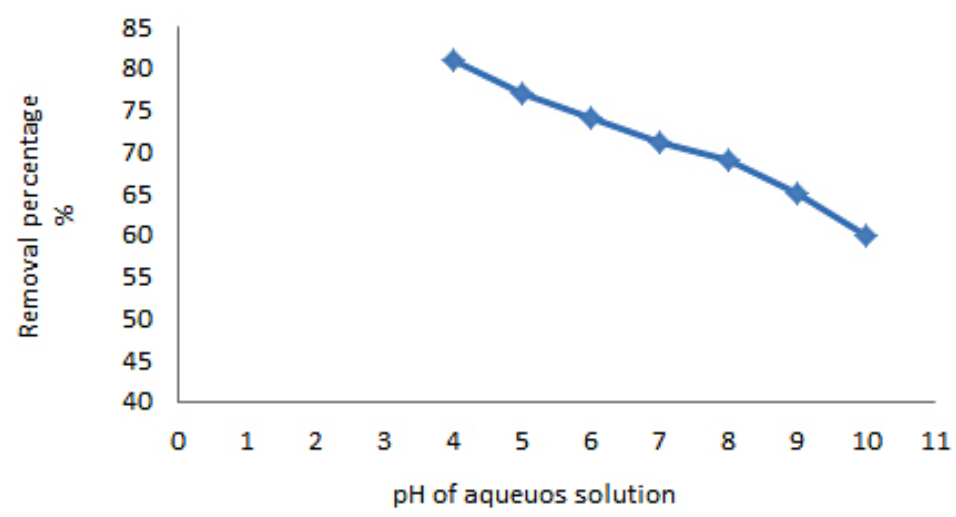

Figure 2. $\mathrm{pH}$ of aqueous solution versus removal percentage 


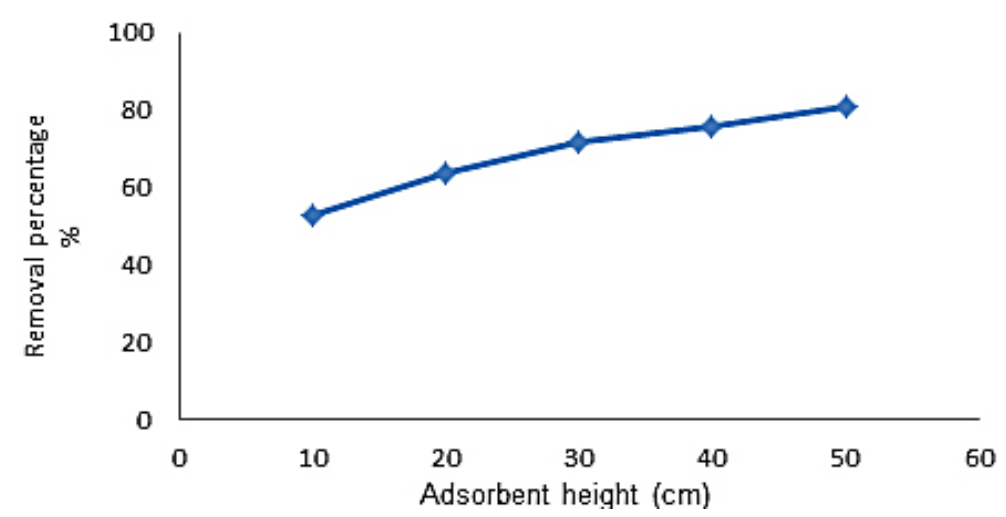

Figure 3. Adsorbent height versus removal percentage

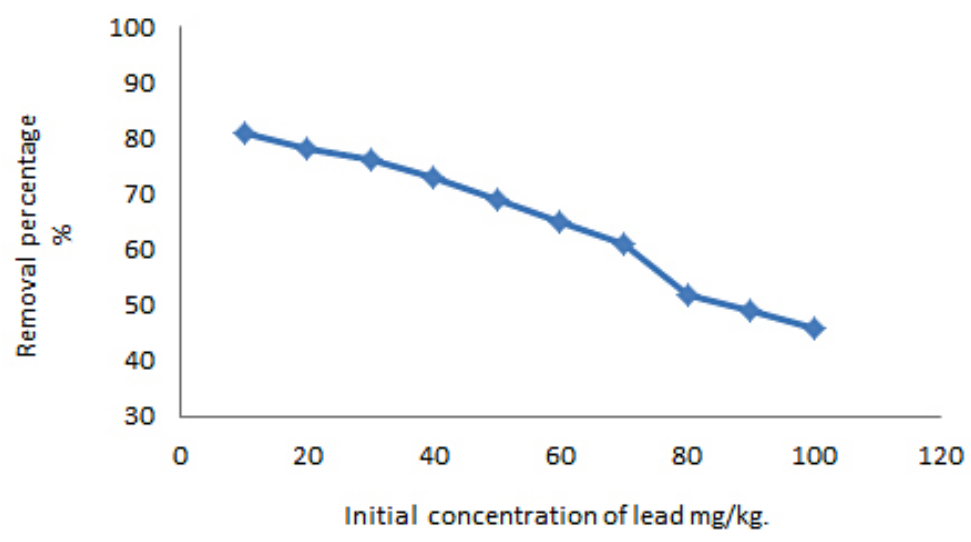

Figure 4. Initial concentration of lead versus removal percentage

$50 \mathrm{~cm}$. The operational conditions were $\left[C_{\circ}(10\right.$ $\mathrm{mg} / \mathrm{l}), \mathrm{pH}(4), \mathrm{t}(90 \mathrm{~min})$ and $\mathrm{Q}(10 \mathrm{ml} / \mathrm{min})]$. Figure 3 illustrates that the adsorption of lead improved due to the increase in the adsorbent material height in column. This is due to increase in the surface area of adsorbent material. The adsorption binding sites will increase along with the adsorbent height in the column, improving the percentage of lead adsorption (Muataz, 2011).

\section{Influence of initial concentration}

The influence of lead concentration on the adsorption process was studied by varying the initial concentration of lead between 10 to 100 $\mathrm{mg} / \mathrm{L}$. The other operational conditions were [pH (4), h $(50 \mathrm{~cm}), \mathrm{t}(90 \mathrm{~min})$ and $\mathrm{Q}(10 \mathrm{ml} /$ $\mathrm{min})$ ]. Figure 4 illustrates that an increase in lead concentration led to a decrease in the lead adsorption efficiency. The concentration of lead has an effect on the adsorption process, where the adsorbent material contains a limited numbers of active sites that may be saturated with a definite concentration. Subsequently, the quantity of competing lead particles of the present functions places on the adsorbent surface increased (Kouakou et al. 2013).

\section{Influence of processing time}

Figure 5 illustrates that the lead adsorption efficiency increased along with the processing time in the experiments. The tests were performed by varying the processing time between 10 to $90 \mathrm{~min},\left[\left(\mathrm{pH}\right.\right.$ (4) h $(50 \mathrm{~cm}), \mathrm{C}_{\text {。 }}(10 \mathrm{mg} / \mathrm{l}), \mathrm{Q}(10$ $\mathrm{ml} / \mathrm{min})$ ]. It was observed that when increasing the processing time, the solution took the suitable time upon contact with the adsorbent material (rice husks). Consequently, the ability of the adsorbing medium to adsorb larger quantities of lead is increased, thus achieving the best removal percentage (Muataz, 2011).

\section{Influence of flow rate}

The influence of flow rate was studied in tests at [pH (4), h (50 cm), C 0 (10 mg/L), t (90 min)], the flow rate was changed between 10 to $60 \mathrm{ml} /$ min. Figure 6 shows the influence of flow rate on the percentage of lead removal. It was noticed that 


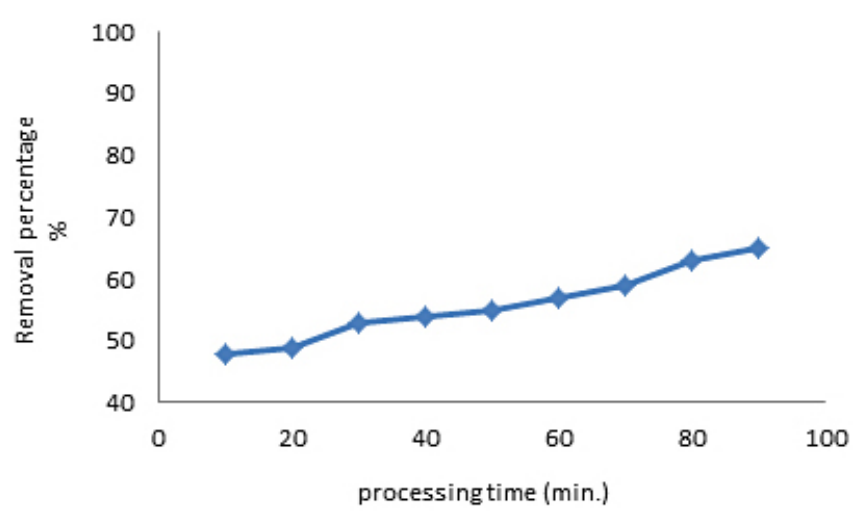

Figure 5. Processing time versus removal percentage

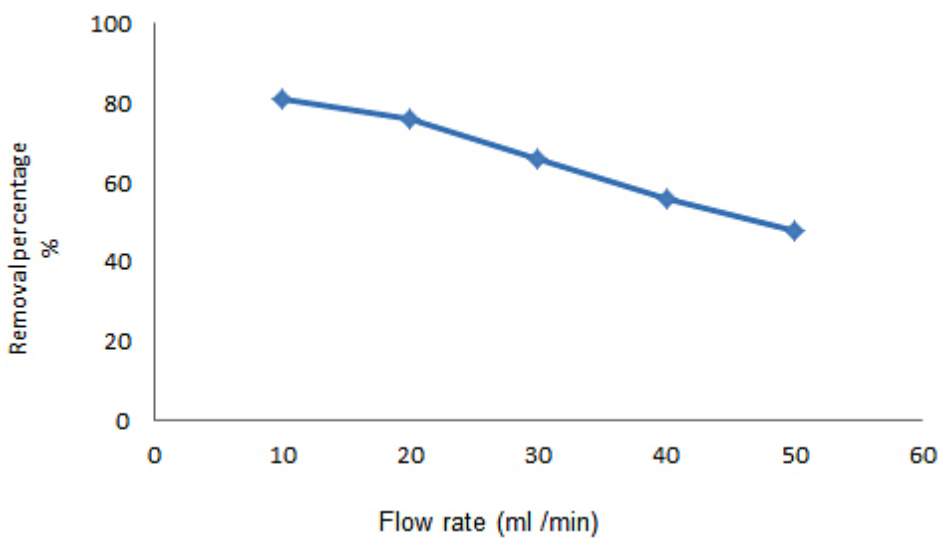

Figure 6. Flow rate versus removal percentage

the velocity of the aqueous solution flow increases with the flow rate. Therefore, the solution was discharged from the column prior the medium adsorbs the suitable quantity of lead from the solution to achieve the greatest removal percentage. In contrast, the flow decreases, the contact time with the adsorbent material (rice husks) increases. Thus, the quantity of lead adsorbed increases and the percentage of lead adsorption improves (Muataz, 2011).

\section{CONCLUSIONS}

This paper demonstrated the success of lead adsorption process from the solution using rice husks by continuous system. The best percentage of lead removal was $(81 \%)$. The adsorption efficiency by rice husks was decreased as the initial concentration of lead, $\mathrm{pH}$ of the solution and the flow rate increased. The removal percentage was decreased along the adsorbent height in the column and the processing time. Finally, the adsorption process by rice husks can be considered useful, inexpensive and environmentally friendly.

\section{Acknowledgments}

The authors are thankful to Mustansiriyah University and laboratories affiliated to the Environmental Engineering Department, College of Engineering. We also send our greetings to editorial board in your journal.

\section{REFERENCES}

1. Burakov A.E., Galunin E.V., Burakova I.V., et al. 2018. Adsorption of heavy metals on conventional and nanostructured materials for wastewater processing purposes: A review. Ecotoxicol. Environ. Saf., 148, 702-712.

2. Dos Santos V.C., Tarley C.R., Caetano J., Dragunski D.C. 2010. Assessment of chemically modified sugarcane bagasse for lead adsorption from aqueous medium. Water Sci. Technol., 62, 457-465.

3. Hawal L.H, Laith S.A.A., Maryam S.K. 2021a. Cadmium ions adsorption from aqueous solutions by Bentonite clay, fixed bed column. Journal of Physics: Conference Series. 1895 (2021), 012040. https://doi.org/10.1088/1742-6596/1895/1/012040

4. Hawal L.H., Lubna A., Serror A.A. 2021 b. 
Application of Batch and continuous systems for removal of chromium from simulated waste water by palm date fibers as biological byproduct. Journal of Green Engineering, 11(2).

5. Hawal L.H., Lubna A., Serror A.A. 2021c. Electrokinetic remediation of nickel from contaminated soil using bio remedies banana peels and surfactant-enhanced. Journal of Ecological Engineering, 22(5), 214-220.

6. Kermani M., Pourmoghaddas H., Bina B., Khazaei Z. 2009. Removal of Copper from aqueous solutions by rice husk ash and activated carbon. Pakistan Journal of Biological Science, 9(10), 1905-1910.

7. Kouakou U., Ello A.S., Yapo J.A., Trokourey A. 2013. Adsorption of iron and zinc on commercial activated carbon. Laboratoire de Chimie Physique, Université Félix Houphouët Boigny. Journal of Environmental Chemistry and Ecotoxicology.

8. Kundu S. \& Gupta A.K. 2005. Analysis and modeling of fixed bed column operations on As(V) removal by adsorption onto iron oxide-coated cement (IOCC). Journal of Colloid and Interface Science, 290(1), 52-60.

9. Muataz A.A. 2011. Removal of Zinc from water using modified and non-modified carbon nano fibers. Chemical Engineering Department Center of Research Excellence in Nanotechnology, King Fahd University of Petroleum \& Minerals, KSA, 2nd International Conference on Environmental Science and Technology IPCBEE, IACSIT Press, Singapore, 6 .

10. Nakbanpote W., Goodman B.A., Thiravetyan P. 2007. Copper adsorption on rice husk derived materials studied by EPR and FTIR. Colloids and surfaces. A Physicochemical and Engineering Aspects, 304, 7-13.

11. Patterson J.W. 1985. Industrial Wastewater Processing Technology. Butterworths, Stoneham, Mass, USA, 2nd edition.

12. Tarasevich Y.I. \& Klimova G.M. 2001. Complexforming adsorbents based on kaolinite, aluminium oxide and polyphosphates for the extraction and concentration of heavy metals ions from water solutions. Applied Clay Science, 19(1-6), 95-101.

13. Yadav D., Kapur M., Kumar P., Mondal M.K. 2013. Adsorptive removal of phosphate from aqueous solution using rice husk and fruit juice residue. Process Safety and Environmental Protection, 94, 402-409. https://doi.org/10.1016/j.psep.2014.09.005 